\title{
Dynamic monitoring of landscape patterns and ecological processes using HJ-1 and SPOT satellite data over Hulunbeier grassland, China
}

\author{
Feng Zhang ${ }^{1}$, Ying Li $^{1,2}$, Sihan LiU ${ }^{1}$, Shaohua ZhaO ${ }^{1, *}$ and Yanting Wu ${ }^{1}$ \\ ${ }^{1}$ Satellite Environment Center, Ministry of Environmental Protection, State Environmental Protection \\ Key Laboratory of Satellite Remote Sensing, Beijing 100 094, China. \\ ${ }^{2}$ College of Resources Science and Technology, Beijing Normal University, Beijing 100875, China. \\ ${ }^{*}$ Corresponding author. e-mail: zshyytt@126.com
}

Landscape patterns and ecological processes have been in long-term research focus in the field of landscape ecology, but how to measure their quantitative relations is still open. This work chooses the Hulunbeier grassland as the study area where ecosystem shows high vulnerability, frequent evolvement of landscape patterns and ecological processes. With remote sensing technology, the relationships between landscape patterns and ecological processes were analyzed quantitatively from multi-scale, multitemporal and time series perspective. Firstly, the information about the current situation and change of landscape patterns and ecological processes are obtained from HJ-1 (Environmental and Disaster Small Satellite) and LANDSAT TM (Thermal Mapper) data. Secondly, SPOT NDVI (Normalized Difference Vegetation Index) data during 2000-2008 are used to analyze the dynamic changes of ecological processes, and to simulate its inter-annual variety at pixel scale. Finally, the dynamic change trends of ecological processes of grassland vegetation are described. The results indicate that the unchanged ecosystem types account for most of the study area, unused land in the central part expands continuously which results in the increase of desertification, and most ecosystem types in the eastern part are changed to grassland and woodland. Furthermore, the vegetation vulnerability is the highest in the grassland-dominated region, the second in grassland-farmland-woodland transition, and the smallest in the woodland-dominated region, where the stability is enhanced in turn. Due to the dynamic change of vegetation, it can be concluded that the study area underwent ecological processes of vegetation cover with a negative trend and a changed phenology.

\section{Introduction}

As a discipline to investigating dynamic changes of ecosystem, landscape ecology mainly concentrates on the interactions between landscape patterns and ecological processes (Fu et al. 2003). Landscape patterns often refer to the spatial patterns of the ecosystem, i.e., the amount and spatial distribution of landscape elements. On the other hand, ecological processes emphasize dynamic features about the occurrence and development of phenomena and events. The formation of landscape patterns reflects various ecological processes, and it can be seen as the cumulative results of ecological processes and transient performance; in turn, ecological processes control and act on landscape patterns. Meanwhile, the patterns affect the evolving processes. Scale plays an important role in

Keywords. Ecosystem; remote sensing; NDVI; change. 
quantitatively analyzing the relationships between landscape patterns and ecological processes, which vary inherently over different scales. Due to the complexity, abstractness and dependence between landscape patterns and ecological processes, it is still difficult to address the dynamic change of ecological processes directly and quantitatively $(\mathrm{Hu}$ et al. 2008). The current work mainly focuses on the simple description of landscape patterns or ecological processes, but integrated and quantitative studies are still lacking.

Hunlunbeier is one of the most famous grasslands in Inner Mongolia of China for its high-quality forages and rich resources. However, influenced by global change and human activities, the grassland degenerated so seriously that the ecosystem vulnerability enhanced rapidly, hence more and more attention was paid to this; many studies have documented the land degradation in Inner Mongolia steppe region (Wu 2003; Zhao et al. 2007; Han et al. 2009; Bagan et al. 2010; Duan et al. 2012; Zhang et al. 2012). For instance, by using two supervised classification methods and four TM remote sensing images from 1975-2007, Bagan et al. (2010) evaluated the dynamics and trends of changes of land cover in the Horqin Sandy Land. Over the last three decades, their analyses revealed significant changes to land cover, and the area of cropland doubled. Large increases in water consumption and considerable loss of areas of grassland and woodland accompanied this expansion. Many lakes and rivers shrank rapidly or disappeared in this region. Whereas, the sandy area expanded rapidly from 1975 to 1987 , the expansion gradually slowed thereafter. Duan et al. (2012) discussed the spatialtemporal evolution of landscape pattern of regional land aeolian desertification by taking five remote sensing images from 1975-2010. The results showed that in the past 35 years, the aeolian desertification area decreased by $123.43 \mathrm{~km}^{2}$ with a reversal trend. Aeolian desertified land mainly experienced a process of increase to decrease at the watershed of 1999; hence the landscape pattern also changed fluctuatingly. Zhang et al. (2012) assessed in detail, the effectiveness of ecological restoration projects in Horqin Sandy Land based on SPOT-VGT NDVI data, their results indicated that the area with degraded vegetation accounted for approximately $10 \%$ of sand dune area, mainly located in the southeast of Jarud Banner and the west of Horqin Left Middle Banner. In addition, the types of sand dunes in degraded status were mainly the fixed and semi-fixed sand dunes, followed by the semi-shifting sand dunes and salinealkali land. Above literature, all demonstrated that when the landscape patterns changed fast, the ecological processes would be also affected heavily. Therefore, Hulunbeier grassland is chosen as the study area to explore its landscape ecological characteristics.

NDVI is an effective indicator of land cover changes (Stow et al. 2007), and satellite remote sensing is a very good tool to obtain NDVI value and monitor ecological environment over a large scale, such as HJ satellite, Landsat TM, SPOT, EOS-MODIS, etc. So we select NDVI to estimate vegetation cover change by using HJ-1 and SPOT satellite data for assessing the landscape patterns and ecological processes in this study.

The paper aims to investigate the evolvement trends of grassland vegetation by analyzing its dynamic changes of the landscape patterns and ecological processes. Section 2 states the study area, used data and its processing methods; and section 3 describes and analyzes the results of the changes between landscape pattern and ecological processes. Conclusion and discussion are provided in section 4.

\section{Study area and data}

\subsection{Study area}

Hulunbeier grassland is located in the west of Daxinganling and the northeast of Inner Mongolia, and consists of Xinbaerhuyouqi, most part of Xinbaerhuzuoqi, Manzhouli, Hailaer, part of Ewenke, Chenbaerhuqi, Eerguna and Yakeshi. Figure 1 illustrates the location of the study area (HJ-1 satellite CCD RGB image in 2008). The study area is also situated in the Eurasia mid-latitude, far away from the ocean; thus most parts have a continental monsoon climate, with annual average temperature within $-0.8^{\circ}$ and $1.8^{\circ} \mathrm{C}$, annual precipitation from 240 to $360 \mathrm{~mm}$, and frost-free season of 90 to 150 days (Zhang and Zhou 2007). Due to the shortage of water resources, the global change and human irrational utilization, landscape patterns of Hunlunbeier grassland changed heavily, which further results in ecosystem destruction, serious grassland degradation and desertification (Zhu et al. 2008).

\subsection{Data and methods}

The data used in this work includes: (1) China HJ-1 CCD images acquired on October 1st 2008, with spatial resolution of the CCD images as $30 \mathrm{~m}$. The data include 4 bands of blue, green, red and near infra; (2) Landsat TM images during the period from May to October in 2000 and (3) SPOT_VGT NDVI data from April to October in 2000 and 2008.

This study aimed at using HJ-1 CCD images $(30 \mathrm{~m})$ at the small scale and SPOT VGT data $(1000 \mathrm{~m})$ at the large scale to investigate the 


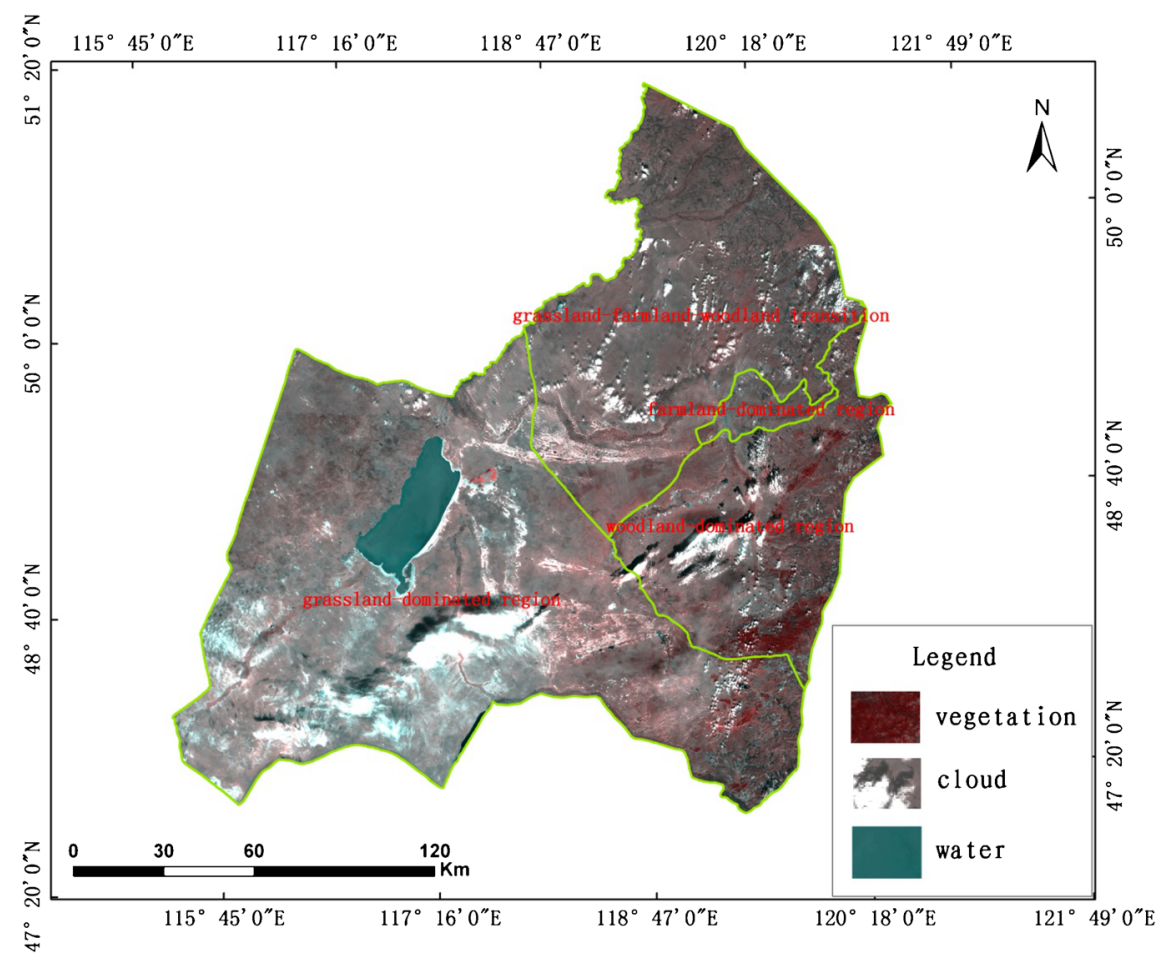

Figure 1. Location of the study area.

dynamic changes of the landscape in the study area from the multi-scale aspect. Methods are as follows: (1) obtaining ecosystem transformation information with satellite images in 2008 and 2000; (2) analyzing the trends from time series NDVI, NDVI dynamic curve and ecological processes using SPOT VGT image; and (3) studying landscape pattern change and ecological process evolvement. Ecosystem landscape pattern transformation at large scale reflect the influencing results of ecological processes during 9 years; time series NDVIs describe the dynamic change processes of landscape patterns at the pixel scale. In addition, NDVI dynamic curves and ecological processes trends characterize the vegetation cover situation and phenology characteristics, which helps to seek the trend of ecological processes development, and to explain the internal mechanism of landscape pattern change. Therefore, the technical system of interaction between landscape patterns and ecological processes is constructed finally.

\subsection{Data processing}

According to administrative district and vegetation types of Hulunbeier grassland, the study area is divided into four subregions to analyze ecological processes: (1) Grassland-dominated region (Xinbaerhuyouqi, Xinbaerhuzuoqi, Manzhouli), (2) grassland-farmland-woodland transition (Chenbarehuqi, Hailaer, Eerguna), (3) woodland-dominated region (Yakeshi, Ewenke), and (4) farmland-dominated region (Hailaer).

In the aspect of landscape patterns, using 2000 and 2008 remote sensing images with geometric correction and image mosaic, the study area is classified into 6 types of ecosystem: farmland, woodland, grassland, water, building and unused land. The supervised classification and visual interpretation methods are combined to classify images. The maximum likelihood method is first used to classify images, and then visual interpretation is applied to correct the classified results (Zong et al. 2009). In order to assess the accuracy of the results, we randomly chose 200 check points, and the classification accuracy was $85.6 \%$.

As for the ecological process, SPOT_VGT NDVI data are used to analyze the dynamic change. As one of the most widely used indices of vegetation, NDVI eliminates most atmospheric, instrument calibration and terrain effects, and is sensitive to vegetation growth status and vegetation types. Moreover, it can also describe vegetation growth process and reflect their phenology characteristics (Paruelo and Lauenroth 1995; Zhang et al. 2004; Huang et al. 2008). Therefore, NDVI is helpful to monitor dynamic changes of vegetation effectively.

The detailed processing steps list is as follows: First, average smoothing method (the mean of adjacent data) is used to eliminate error, remove the abnormal value (cloud coverage) and 
generate time series data from 2000 to 2008. Second, three indicators are first extracted to describe vegetation cover according to annual NDVI seasonal curve. They are: (1) the annual mean NDVI (NDVI-I) (Paruelo and Lauenroth 1995), a good estimator of annual fAPAR and thus of NPP, reflecting vegetation coverage status; (2) the date of maximum (DMAX) and minimum (DMIN) NDVI values, two descriptors of the phenology of vegetation (Alcaraz-Segura et al. 2009). Third, Mann-Kendall trend test (Zhang and Zhou 2007) is adopted to analyze the trend of the three indicators and ecological process during 2000 to 2008. This test can find the existence of a monotonic temporal trend based on Kendall's tau statistic with alpha level being 0.05 .

\section{Results and analysis}

\subsection{Dynamic change of landscape patterns}

Landscape can be seen as a heterogeneous area composed of many ecosystems or a mosaic consisting of various land use types. Ecosystem transformation represents the changing conditions of landscape patterns at different times. Therefore, based on the classification results, ecosystem classification figure in 2000 and 2008 can be generated, and so their spatial distributed information of six land use types (figure 2).

Figure 3 shows the difference of the two periods of ecosystem classification data, and table 1 illustrates the ecosystem transition matrix during 2000 to 2008 in the study area.

The results of ecosystem transformation from 2000 to 2008 (figure 3) indicated that six types of landscape patterns have changed greatly. From the perspective of spatial distribution, transformed landscape patches occupied most parts of the study area, increasing from west to east, and assembled in the eastern long narrow strip. From the perspective of landscape types, the eastern long narrow strip is mainly transformed to woodland and grassland. The central part is mainly converted to unused land (sand dominated), of which the majority is grassland, and water is changed to sand. Grassland in the western part is mainly transformed to other ecosystem types while the area is relatively small. From the perspective of transformed area, unchanged ecosystem (white area) mainly dominates the study area (almost 79.97\%). In general, most ecosystem types are basically changed to unused land (brown), woodland (dark green) and grassland (light green), whose areas are $2.60 \%, 5.22 \%, 8.63 \%$ of the total area, respectively. From the perspective of single landscape, grassland is preserved well with $89.13 \%$ unchanged ratio; whereas, woodland and farmland changed much, and $57.35 \%$ and $59.48 \%$ of the total are transformed to other landscape types, with most being transformed to grassland. Besides, $26.20 \%$ water is transformed to unused land, indicating a sharp reduction in the water which might be detrimental to vegetation growth.

\subsection{Dynamic change of vegetation cover}

Although ecosystem transformation reflected landscape patterns evolvement quantitatively on a spatial scale, the results only compared two periods' data that cannot efficiently depict the dynamic changing process. Consequently, to measure the temporal features of dynamic landscape patterns, SPOT_VGT data from April to October in 2000 to 2008 are used to compute annual mean NDVI (NDVI-I) and obtain time series figure of Hulunbeier grassland annual mean NDVI (figure 4). Colours in this figure, ranging from orange to green, represent NDVI value from low to high.

In terms of the spatial configuration of NDVI, annual NDVI-I transit from light green to orange demonstrates that NDVI value reduces gradually from east to west, which further means a decrease in vegetation cover. In the aspect of ecological processes, annual mean NDVI was reduced with a high rate annual mean NDVI during 2000 to 2001. That is, the western buff area expanded while orange area increased, especially in Xinbaerhuyouqi where NDVI value is reduced to 0.202 from 0.247 . The central orange area increased while buff area reduced, and the eastern light green area also reduced. These indicate that vegetation coverage reduced and grassland desertification area increased. From 2002 to 2004, annual mean NDVI reduced as well, western orange area expanded which almost covered the whole Xinbaerhuyouqi, central orange area increased, and white area (Lake Hulun) shrunk. Whereas, eastern light green area changed a little, indicating that western vegetation coverage reduced while central grassland changed to sand and eastern vegetation had a low change rate where moderate and low vegetation still dominate the area. During 2005 to 2008, annual mean NDVI increased gradually, the western orange area reduced, especially in Xinbaerhuyouqi, Xinbaerhuzuoqi and Manzhouli, and the central orange area reduced too, but the light green area increased. However, eastern part of Lake Hulun was already replaced by orange area, and the increase of eastern green area indicated that vegetation coverage in the study area had recovered. Generally speaking, vegetation, water and sand underwent significant ecological processes; the grassland reduced firstly and then increased, but it remains faced with desertification. Buff 

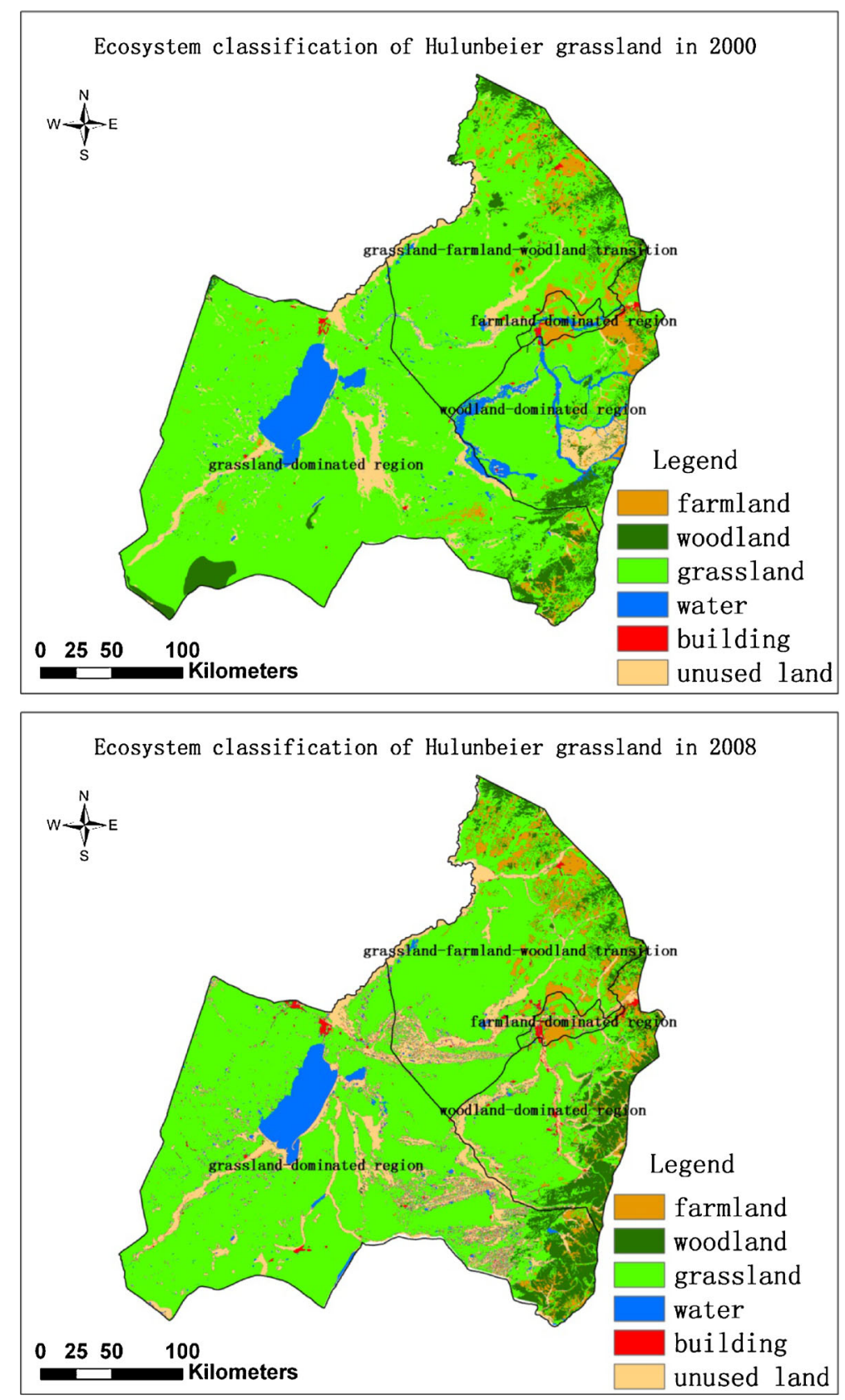

Figure 2. Ecosystem classification of Hulunbeier grassland in 2000 and 2008.

area expanded towards eastern part indicating low vegetation coverage spread increasingly. What is worse, water has been reducing during these years intensifying the desertification further.

On the other hand, NDVI-I dynamic curve (see figures 5a, b, c, excluding Hailaer) can help to analyze the inter-annual dynamic change of vegetation in the aspect of counties. As shown in figure 5, from the perspective of NDVI-I value, the woodland-dominated region is the first, followed by grassland-farmland-woodland transition, while the grassland-dominated region is the last. This result tallies with regional vegetation types. The curve's fluctuation respects the following order: grassland-dominated region $>$ grassland-farmland-woodland transition > woodland-dominated region, indicating the three regions' vegetation stability increased gradually. In vegetation change trends aspect, the grasslanddominated region represents the negative trend from 2000 to 2004, while the lowest NDVI-I value appeared in 2001 and 2004, and then NDVI-I increased from 2005 to 2008; grassland-farmlandwoodland transition is relatively stable, vegetation changed a little; NDVI-I in the woodlanddominated region trends to be negative during 2000 to 2002, implying vegetation reduction, while it is positive from 2002 to 2008 , meaning vegetation 


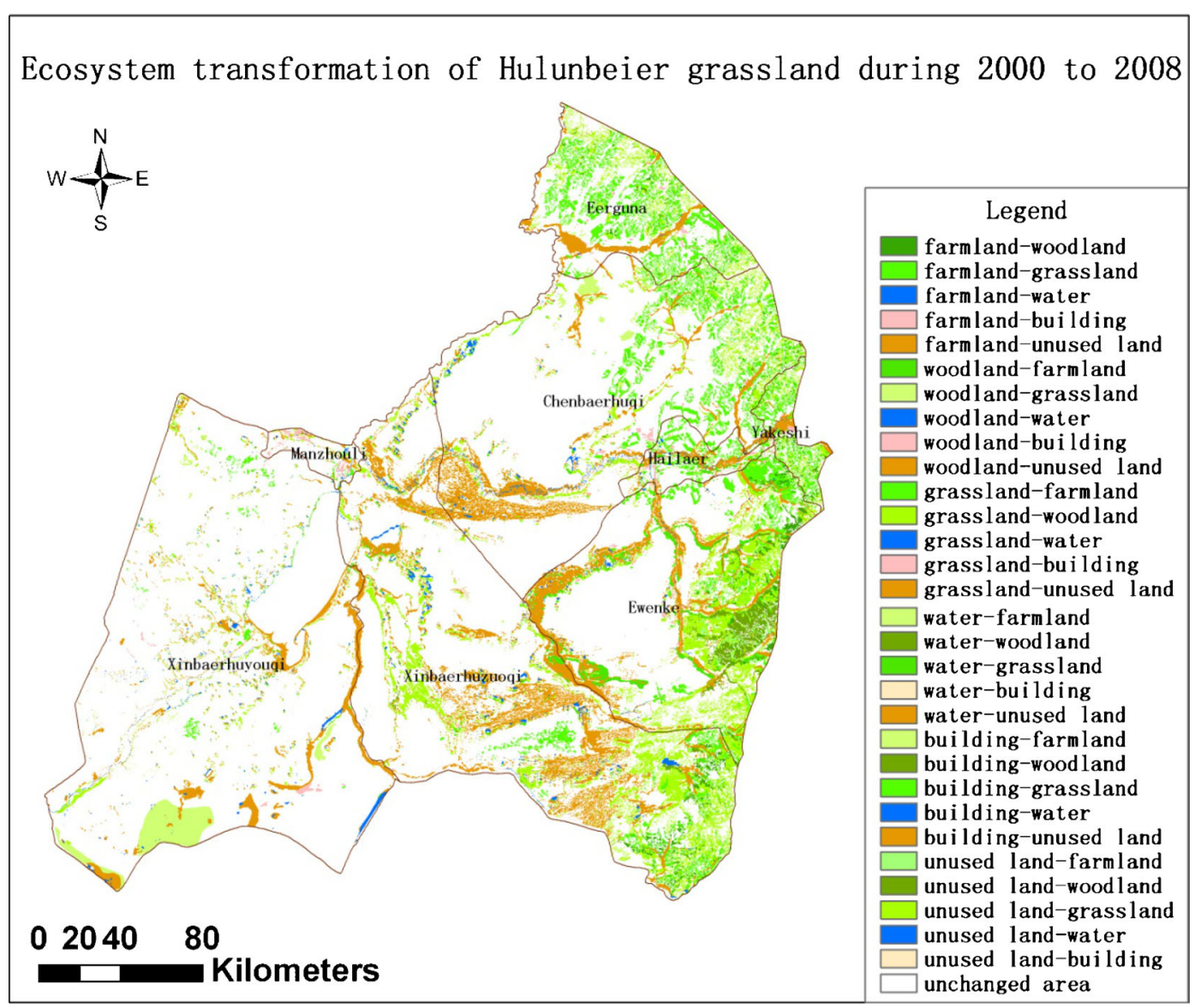

Figure 3. Ecosystem transformation during 2000 to 2008 in Hulunbeier grassland.

Table 1. Land cover and land use transition matrix of Hulunbeier grassland in 2000-2008 (unit: \%).

\begin{tabular}{|c|c|c|c|c|c|c|}
\hline 2000-2008 & Farmland & Woodland & Grassland & Water & Building & Unused land \\
\hline Farmland & 40.52 & 13.06 & 40.24 & 0.17 & 1.38 & 4.63 \\
\hline Woodland & 9.67 & 42.65 & 40.72 & 0.48 & 0.18 & 6.29 \\
\hline Grassland & 4.04 & 4.99 & 89.13 & 0.70 & 0.57 & 0.57 \\
\hline Water & 1.15 & 3.09 & 17.27 & 51.27 & 1.01 & 26.20 \\
\hline Building & 15.67 & 3.64 & 35.53 & 2.04 & 33.00 & 10.27 \\
\hline Unused land & 2.72 & 8.57 & 35.86 & 2.77 & 0.43 & 49.65 \\
\hline
\end{tabular}

increased gradually. In time scale aspect, vegetation reduced severely in the grassland-dominated region from 2000 to 2001. During the period, vegetation in grassland-farmland--woodland transition and woodland-dominated region also reduced, of which grassland changed a lot while woodland a little; from 2002 to 2004, vegetation in the grassland-dominated region still reduced, and in 2004 NDVI-I reached the minimum value; whereas, vegetation in grassland-farmlandwoodland transition and woodland-dominated region changed slightly; during 2004 to 2008, vegetation coverage in all regions increased, especially the recovery of grassland, as most orange area are converted to light green (figure 4). Therefore, ecological environment is becoming better. Woodland in the grassland-farmland-woodland transition and the woodland-dominated region changed a little while grassland recovered. In conclusion, grassland in the study area reduced firstly and then increased, however, farmland and woodland changed steadily from 2000 to 2008.

\subsection{Trends in grassland ecological processes}

Ecosystem transformation and time series NDVI showed dynamic change of landscape patterns 


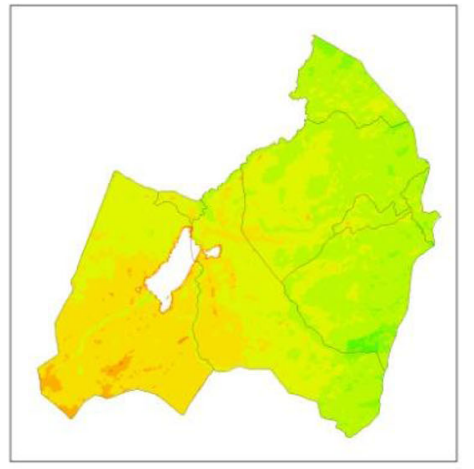

2000

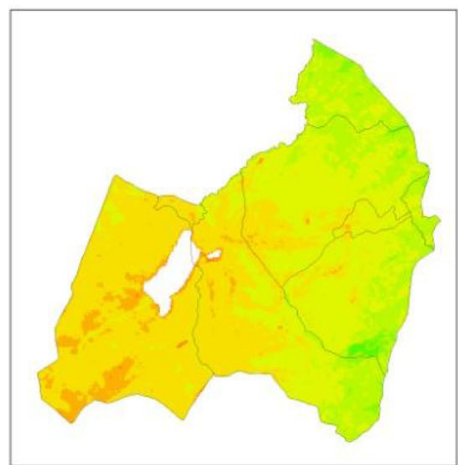

2003

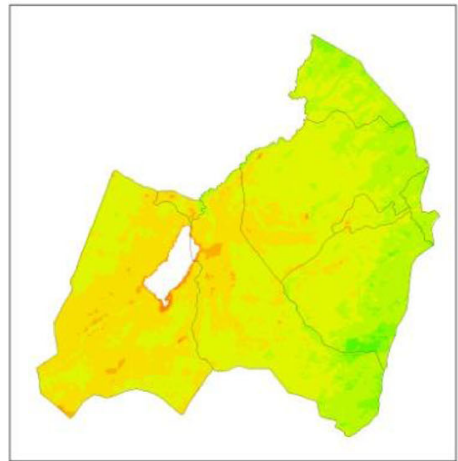

2006

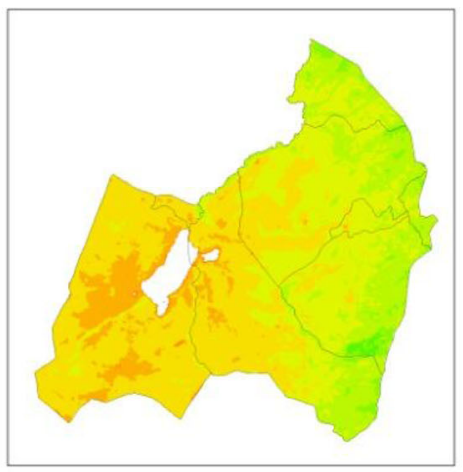

2001

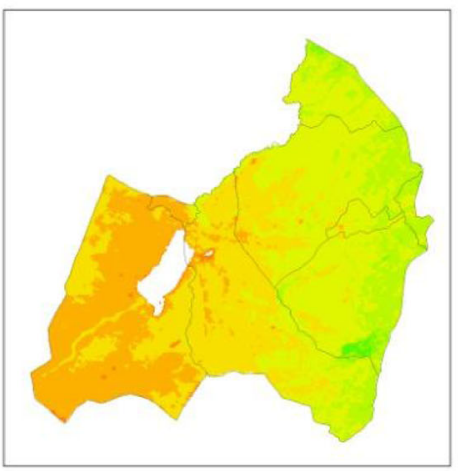

2004

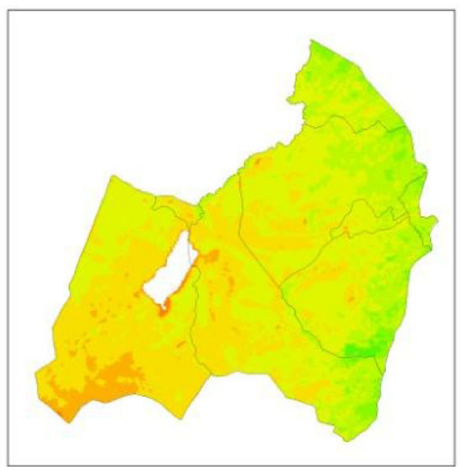

2007

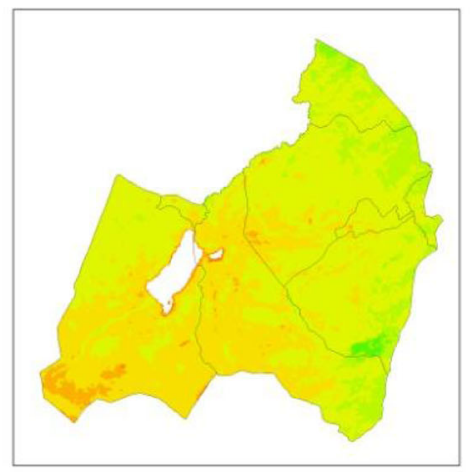

2002

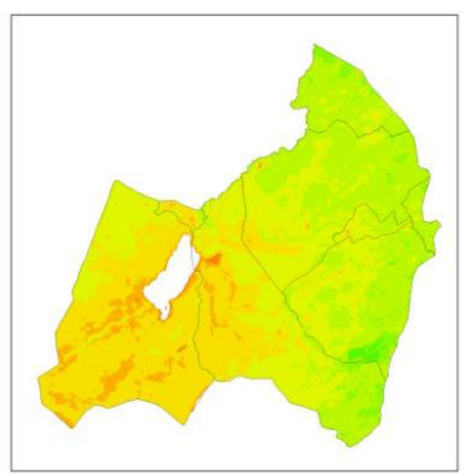

2005

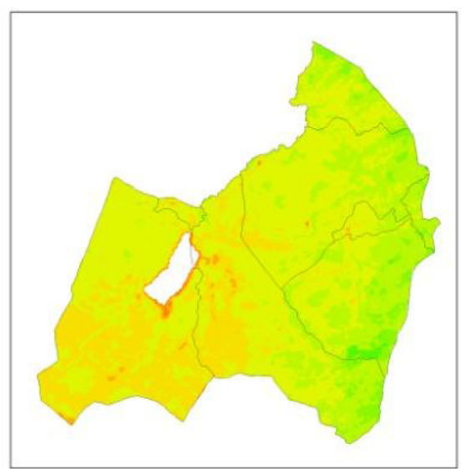

2008

Figure 4. Time series NDVI of Hulunbeier grassland from 2000 to 2008.

directly and represented ecological processes as the transition of landscape. However, this analysis cannot reflect the features and laws of internal changing of ecological processes. Accordingly, MannKendall trend test is used to compute the trends of NDVI-I, DMAX and DMIN from 2000 to 2008 (figure 6), which express the hidden features of ecological processes.

As shown in figure 6, Y-axis represents the percentage of pixels showing significant trend, and $\mathrm{X}$-axis refers to the counties. In general, NDVI-I and DMAX show negative trend in the study area while DMIN positive trend indicate that NPP and phenology of vegetation had a remarkable change. Specifically, for NDVI-I, the negative trend in the study area ranges from $29.598 \%$ to $76.590 \%$. Each county shows significant trend with percentage greater than $50 \%$ except for Yakeshi and Xinbaerhuzuoqi, which indicated the study area went through an ecological process at both large (study area) and small scales (county): NDVI-I appeared negative and vegetation coverage reduced with fAPAR and NPP decreasing. For DMAX, although pixels with positive trend appeared in every county, the percentage is small. DMAX in the study area still showed negative trend with a value ranging from $20.834 \%$ to $52.714 \%$. Moreover, the number of pixels with positive trend is larger than that with negative trend. The above results implied the following ecological process: DMAX has negative trend and the date of maximum NDVI value tends to occur earlier in summer, that is, phenology in the study area has changed. For DMIN, pixels with negative trend are 


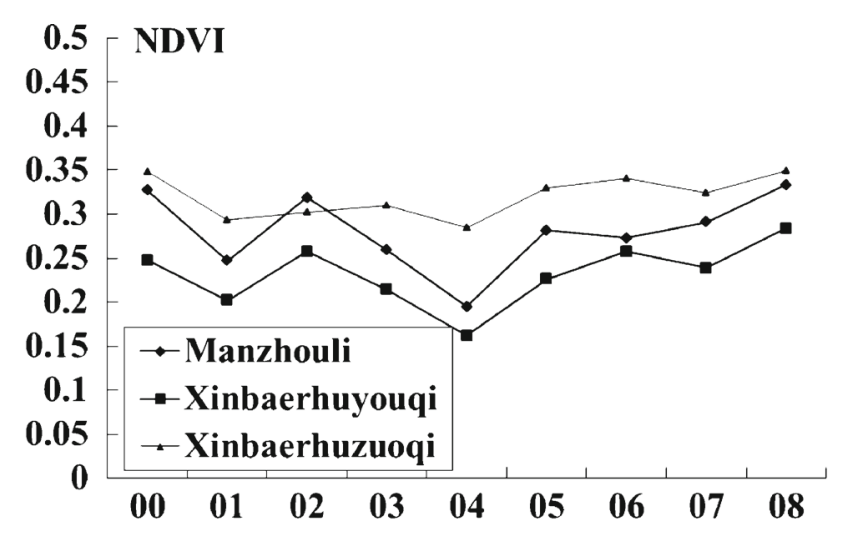

(a) grassland-dominated region

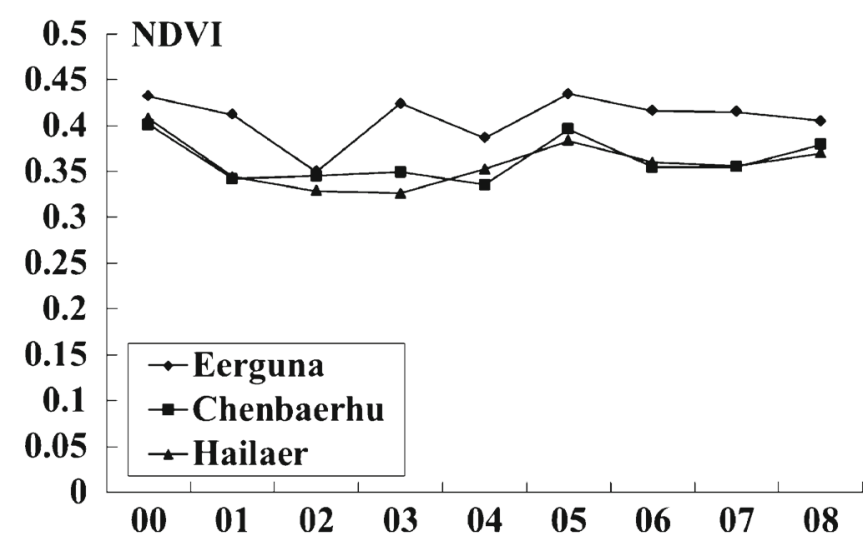

(b) grassland-farmland-woodland transition

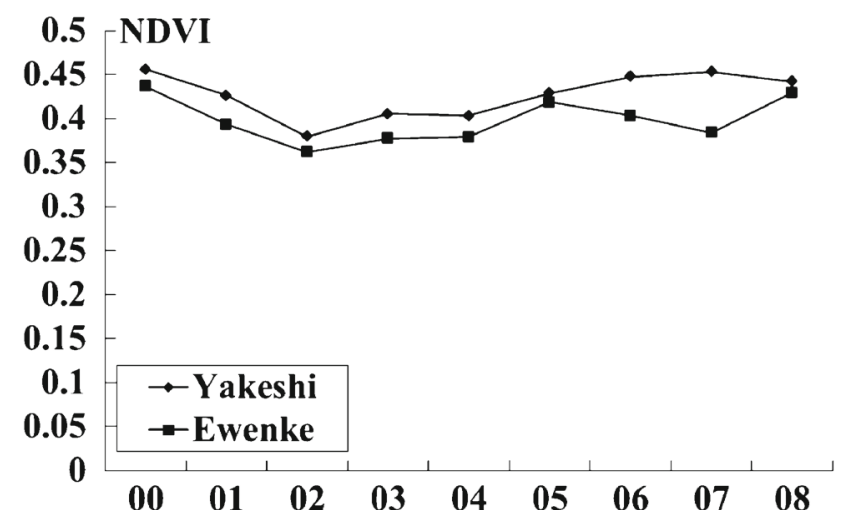

(c) woodland-dominated region

Figure 5. NDVI-I dynamic curves of each counties in Hulunbeier grassland.

much less than those with positive trend. The main grassland region has significant positive trend with value ranging from $22.946 \%$ to $70.188 \%$. This indicated that an ecological process occurs at a small scale as follows: DMIN in the main grassland shows positive trend and the minimum value of NDVI tends to occur later in autumn, thus the phenology in the main grassland has changed as well. Based on the above results, the study area went through a variety of ecological processes at different scales: NPP and fAPAR reduced as well as vegetation phenology changed from 2000 to 2008.

An examination of the meteorological data indicated that the temperature increased and the precipitation decreased in the study area. Therefore, these changes may influence the dynamic change of the grassland coverage and its phenology, which in turn changed the NDVI-I and DMAX. Because there is a relatively small population with a very low rate of growth, the influence of local residents is relatively less than that of the natural factors (meteorological data). As a result, it appears that the climatic change may account for the grassland change.

\subsection{Synthetic analyses of landscape patterns and ecological processes}

Landscape patterns are the accumulation of ecological processes which can be seen as its transient performance in some degree. They convert to each other and have a close connection. Natural substances cycle such as energy cycle, water cycle, etc., reflect the ecological processes. Moreover, landscape patterns are the final result induced by ecological processes. However, it is difficult to monitor the dynamic change of substances cycle using remote sensing technology. For ecological processes of grassland ecosystem, monitoring its dynamic changes is a good choice for assessing the ecological processes. In this study, time series NDVI and NDVI-I dynamic curve are used to monitor the ecological processes, and ecosystem classification is adopted to monitor landscape patterns. With the combination of the above two indicators, the relationship between the landscape patterns and ecological processes is analyzed.

The above analysis can reflect the dynamic changes of landscape patterns and ecological processes; thus according to the landscape changing degree, Xinbaerhuzuoqi (high) and Ewenke (low) are chosen to make a synthetic analysis. For Xinbaerhuzuoqi, during 2000 to 2008, its grass patches in northern and southern parts are transformed to sand gradually (see brown area in figure 3). Based on time series NDVI (figure 4), from 2000 to 2001, yellow and buff area in Xinbaerhuzuoqi increased visibly whereas green area decreased sharply, implying a high rate of vegetation reduction; from 2002 to 2004, buff area reduced while yellow area increased, indicating that some vegetation coverage was recovered, but the whole grassland degenerated, especially the obvious sand strip (buff area); from 2005 to 2008 , buff area reduced gradually and vegetation recovered, but sand strip still covers a large 

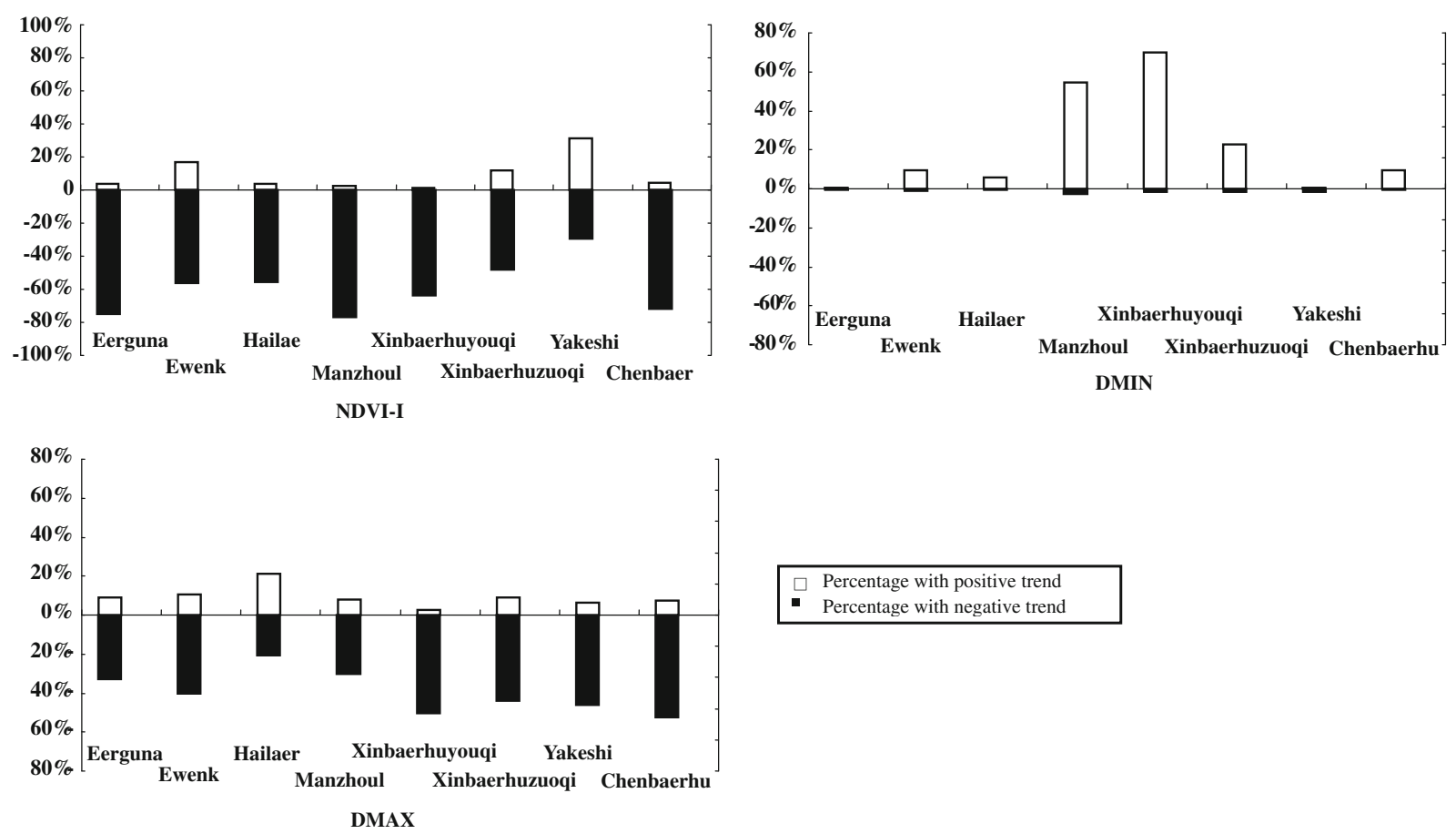

Figure 6. Trends of dynamic changes in the study area during 2000-2008.

area. During this period, NDVI-I dynamic curve (figure 5) also showed the changing process of vegetation. The NDVI, DMAX from ecological processes trend test (figure 6) show significant and negative trend in Xinbaerhuzuoqi whose phenology changed. For Ewenke, unchanged ecosystem types dominate its western part (figure 3), which also can be seen from the NDVI-I dynamic curve (figure 4). From 2000 to 2008, unchanged ecosystem types have always been dominated by buff area, in addition, there is no colour mutation indicating this county has stable vegetation. According to NDVI-I dynamic curve (figure 5), vegetation in Ewenke shows steady inter-annual fluctuation compared with other counties, which is consistent with its large unchanged area and stable woodland, resulting from the results of ecological processes trend test (figure 6). NDVI-I and DMAX show negative trend indicating vegetation and changed phenology tend to decrease. As a result, the above analysis can be used to research landscape patterns and ecological processes effectively.

\section{Conclusion and discussion}

For the vegetation in grassland ecosystem, with multi-scale, multi-temporal and time series NDVIs, this study investigated in detail, the features of landscape patterns evolvement and ecological processes under the analysis of ecosystem transformation, vegetation time series analysis, dynamic change of inter-annual NDVI and ecological processes trend test. The method not only combines the facts but also considers characteristics of vegetation growth. Moreover, we analyzed the landscape ecology of the study area systematically and provided good analysis methods for the grassland landscape patterns and ecological processes.

According to the results of landscape patterns and ecological processes, Hulunbeier grassland continues to deteriorate with severe desertification and degradation. During the period from 2000 to 2008, the negative trend of annual mean NDVI in Hulunbeier grassland indicated that vegetation coverage reduced gradually, and high vegetation coverage expanded to moderate and low coverage, which enhanced the vulnerability of ecosystem. That is, sand in the central part increased and expanded to neighbouring area; woodland and grassland in the eastern part frequently transformed to each other. However, woodland reduced finally; grassland in the western part generally degraded while a small part recovered. Therefore, it is necessary to improve environmental protection and governance.

\section{Acknowledgements}

The study is funded by the National Natural Science Foundation of China (40801072 and 41101313). The authors are grateful to the fruitful comments by the editors and anonymous reviewers. 


\section{References}

Alcaraz-Segura D, Javier C, Paruelo J M and Miguel D 2009 Use of descriptors of ecosystem functioning for monitoring a national park network: A remote sensing approach; Environ. Manag. 43 38-48.

Bagan H, Takeuchi W, Kinoshita T, Bao Y H and Yamagata Y 2010 Land cover classification and change analysis in the Horqin sandy land from 1975 to 2007; IEEE Journal of Selected Topics in Applied Earth Observations and Remote Sensing 3(2) 168-177.

Duan H C, Wang T, Xue X, Guo J and Wen X 2012 Spatial-temporal evolution of aeolion desertification and landscape pattern in Horqin sand land: A case study of Naiman Banner in Inner Mongolia; Acta Geogr. Sinica. 67(7) 917-928 (in Chinese).

Fu B J, Chen L D, Wang J, Meng Q H and Zhao W W 2003 Land use structure and ecological process; Quat. Sci. 23(3) 247-255 (in Chinese).

Han Z, Wang T, Yan C, Liu Y, Liu L, Li A and Du H 2009 Change trends for desertified lands in the Horqin Sandy Land at the beginning of the twenty-first century; Environ. Earth Sci. 59 1749-1757.

$\mathrm{Hu}$ W W, Wang G X and Deng J 2008 Advance in research of the relationship between landscape patterns and ecological process; Process Geogr. 27(1) 18-24 (in Chinese).

Huang Y, Yao J and Chen J H 2008 NDVI time series analysis of representative ground object in Anhui province; J. Anhui Agri. Sci. 36(20) 8843-8846 (in Chinese).

Paruelo J M and Lauenroth W K 1995 Regional patterns of normalized difference vegetation index in
North American shrublands and grasslands; Ecology $\mathbf{7 6}$ 1888-1898.

Stow D, Petersen A, Hope A, Engstrom R and Coulter L 2007 Greenness trends of Arctic tundra vegetation in the 1990: Comparison of two NDVI data sets from NOAA AVHRR systems; Int. J. Remote Sens. 28 48074822.

Wu W 2003 Dynamic monitor to evolvement of sandy desertified land in Horqin region for the last 5 decades, China; J. Desert Res. 23 646-651.

Zhang G L, Dong J W, Xiao X M, Hu Z M and Shedon S 2012 Effectiveness of ecological restoration projects in Horqin Sandy Land, China based on SPOT-VGT NDVI data; Ecol. Eng. 38(1) 20-29.

Zhang F, Wu B F, Liu C L and Luo Z M 2004 Methods of monitoring crop phonological stages using time series of vegetation indicator; Trans. Chinese Soc. Agr. Eng. 20(1) 155-159 (in Chinese).

Zhang L and Zhou Y 2007 Mann-Kendall examination and application in the analysis of the time series for silt concentration in the river; Subtropical Soil and Water Conservation 29(3) 19-22 (in Chinese).

Zhao H, Su Y, Zhang H, Zhao L and Zhou R 2007 Multiple effects of shrub on soil properties and understory vegetation in Horqin sand land, inner Mongolia; J. Desert Res. 27 385-390.

Zhu L F, Wang S X, Wang Y and Zhang W 2008 Thinking about Hulunbeier grassland protection countermeasures; Grass Cultivation and Pasturage 5 27-31 (in Chinese).

Zong X Y, Liu G H, Qiao Y L and Lin S 2009 Study on dynamic changes of wetlands landscape pattern in Yellow River delta; Geo-information Science 11(1) 91-97 (in Chinese). 